CORRECTION

\title{
Correction: Hafting of Middle Paleolithic tools in Latium (central Italy): New data from Fossellone and Sant'Agostino caves
}

\section{The PLOS ONE Staff}

\section{Notice of Republication}

An incorrect version of Fig 1 was published in error. Additionally, a Supporting Information file was incorrectly included in the originally published article. The publisher apologizes for these errors. This article was republished on September 27, 2019 to correct for these errors. Please download this article again to view the correct version.

\section{Reference}

1. Degano I, Soriano S, Villa P, Pollarolo L, Lucejko JJ, Jacobs Z, et al. (2019) Hafting of Middle Paleolithic tools in Latium (central Italy): New data from Fossellone and Sant'Agostino caves. PLoS ONE 14(6): e0213473. https://doi.org/10.1371/journal.pone.0213473 PMID: 31220106

\section{G OPEN ACCESS}

Citation: The PLOS ONEStaff (2019) Correction: Hafting of Middle Paleolithic tools in Latium (central Italy): New data from Fossellone and Sant'Agostino caves. PLOS ONE 14(10): e0223714. https://doi.org/10.1371/journal.pone.0223714

Published: October 3, 2019

Copyright: ๑ 2019 The PLOS ONE Staff. This is an open access article distributed under the terms of the Creative Commons Attribution License, which permits unrestricted use, distribution, and reproduction in any medium, provided the original author and source are credited. 